\title{
Optimizing Access to Space: Ground-to-Orbit Logistics Framework (GOLF)
}

louri Pigulevski

DLTECH Institute, Yverdon-les-Bains, Switzerland.

\begin{abstract}
In terms of the required energy and cost, reaching Earth orbit from the ground continues to be a fundamental obstacle hampering the use of space and its exploration at large. A strategic approach to overcoming this obstacle and making access to space affordable, both for orbital use and deep space exploration, is proposed and substantiated.
\end{abstract}

Keywords: access to space, ground-to-orbit logistics, laser ablation propulsion

\section{INTRODUCTION}

- he science fiction novel "Blowups Happen" by Robert A. Heinlein written in 1940 focalizes on the newly achieved technological capabilities of orbiting large payloads.

There is the following dialogue in the novel:

"Aha," I said. "I see your problem. If you can get a ship into orbit, you're halfway to the Moon."

"No," Bob said. "If you can get your ship into orbit, you're halfway to anywhere."

The last phrase became proverbial in the space community.

How much $\Delta \mathrm{V}$ does it take to go from the Earth's orbit to Mars, which is to travel a distance more than 56 million kilometers? It takes about $3.6 \mathrm{~km} / \mathrm{s}$.

How much $\Delta \mathrm{V}$ does it take to go from the surface of Earth to the low Earth orbit (LEO) and stay there? It takes from 9.3 to $10.0 \mathrm{~km} / \mathrm{s}$ (includes the depth of Earth's gravity well, plus atmospheric and gravity drags), which is considerably more than what is needed to go to Mars or any other planet in our solar system from the Earth's low orbit.

From LEO, where can one travel having $9.3 \mathrm{~km} / \mathrm{s}$ of $\Delta V$ ? One can travel to infinity (Table 1).

In addition to the principal $\Delta \mathrm{V}$ considerations, there are also those related to the stark practical differences between the ground-to-orbit and in-space flights including their pertinent spacecraft designs and types of propulsion, modes of operation, and multitude of other technical aspects.

It turns out that reaching the Earth's orbit from the ground, in terms of the required energy and cost, remains the fundamental problem (the bottleneck!), hampering the industrialization of space and its exploration at large.

To make space access truly affordable, one cannot avoid tackling this bottleneck problem decisively.

The words "inexpensive," "cheap," and "affordable" in relation to space access represent a threshold where there is no longer an insuperable cost disincentive in considering alternatives to specific space mission requirements. ${ }^{2}$

According to NASA criteria, ${ }^{2,3}$ a nonlinear change in launch market demand relative to the payload specific cost at LEO (market elasticity) would well establish itself at the specific cost level of approximately $\$ 2,200 / \mathrm{kg}$ ( $\$ 600 / \mathrm{lb}$ FY93 inflation adjusted), which is a benchmark for second-generation launch systems.

At specific cost level of approximately $\$ 370 / \mathrm{kg}$ (\$100/lb FY93 inflation adjusted), a sufficient return-on-investment, and the subsequent development of profitable commercial launch architectures would become self-sustaining (third-generation launch systems). Further drop in specific cost to $\sim \$ 37 / \mathrm{kg}$ (\$10/lb FY93 inflation-adjusted) would be necessary to approach the "aircraft-like" performance (fourth-generation launch systems).

LEO is defined as circular orbits in the range of $200-400 \mathrm{~km}$ with the lower threshold mostly applied.

\section{GROUND-TO-ORBIT LOGISTICS FRAMEWORK CONCEPT}

Complete separation of the ground-to-orbit leg of flight from the in-space flight would provide a simple, overarching, and very logical approach to the access-to-space problem, which can serve most of the space-related needs. Such a separation would imply creating an intermediate logistics facility at low orbit dubbed the orbital logistics hub (OLH) where the ground-to-orbit flights will end and the in-space flights will commence. OLH would include, among other parts, the orbital

(c) Iouri Pigulevski 2017; Published by Mary Ann Liebert, Inc. This article is available under the Creative Commons License CC-BY-NC (http://creativecommons.org/licenses/ by-nc/4.0). This license permits non-commercial use, distribution and reproduction in any medium, provided the original work is properly cited. Permission only needs to be obtained for commercial use and can be done via RightsLink. 
Table 1. Values of $\Delta V$ Required for Reaching the Solar System Planets from LEO (Excerpt from the Published Table ${ }^{1}$ )

\begin{tabular}{l|c|c|c} 
Destination & $\begin{array}{c}\text { Orbital } \\
\text { Radius (AU) }\end{array}$ & $\begin{array}{c}\text { V Exiting } \\
\text { LEO }\end{array}$ & $\begin{array}{c}\Delta \text { V from } \\
\text { LEO }\end{array}$ \\
\hline Mercury & 0.39 & 13.3 & 5.5 \\
\hline Venus & 0.72 & 11.2 & 3.5 \\
\hline Mars & 1.52 & 11.3 & 3.6 \\
\hline Jupiter & 5.2 & 14.0 & 6.3 \\
\hline Saturn & 9.54 & 15.0 & 7.3 \\
\hline Uranus & 19.19 & 15.7 & 8.0 \\
\hline Neptune & 30.07 & 16.0 & 8.2 \\
\hline Pluto & 39.48 & 16.1 & 8.4 \\
\hline Infinity & $\infty$ & 16.5 & 8.8 \\
\hline AU, & &
\end{tabular}

$A U$, astronomical unit; LEO, low Earth orbit.

shipyard and spaceport. To support the OLH operations, the ground logistics hub (GLH) will be established as an integral part of ground-to-orbit logistics framework (GOLF).

GOLF will allow the following main operations:

(1) Shipping standard space cargo containers from the GLH to OLH and back.

(2) Assembling at OLH the purpose-tailored in-space flight missions, deep, and orbital.

(3) Launching the in-space missions to their destinations.

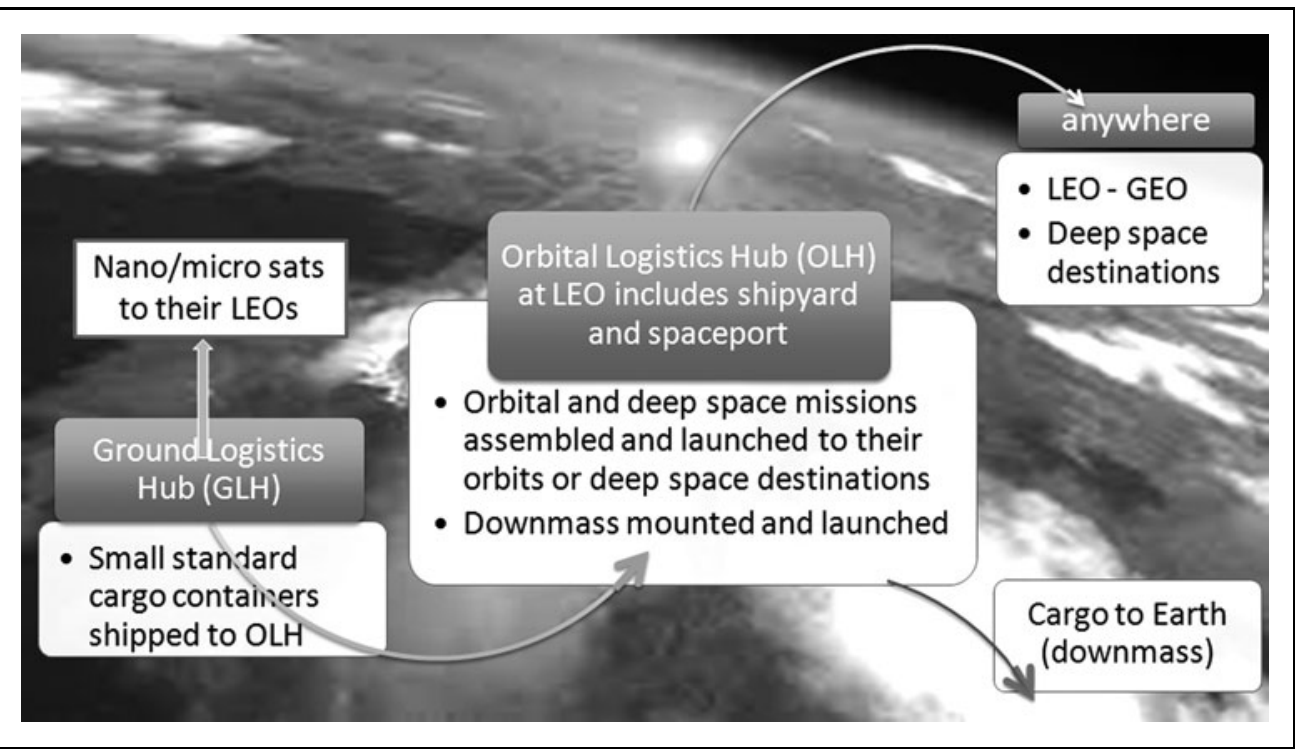

Fig. 1. GOLF concept schematic outline. GOLF, ground-to-orbit logistics framework.
Thereby, GOLF is positioned to entirely eliminate the inspace missions' weight, size, and shape constrains while its GLH-to-OLH shipping leg will operate both ways as a standard space cargo container feeder line.

In addition to shipping standard containers to OLH, GLH can be used to launch the nano/microsatellites directly to their orbits and to beam energy to the satellites at LEO to correct their orbital positions or recharge batteries as the important lines of business.

OLH will comprise several major blocks handling their pertinent types of operations.

(1) Series of the cargo docks to receive the standard cargo containers from GLH and returning the containers back to Earth.

(2) A couple of docks for transferring people and nonstandard cargos in and out.

(3) Sizable indoor and outdoor cargo handling and storage facilities.

(4) Expandable industrial facilities.

(5) Shipyard made of several clean rooms for assembling the in-space missions.

(6) Spaceport for launching the tailor-made missions of any size or shape.

(7) Habitat for the shift working personnel, visiting researchers, and tourists.

It might be true that GOLF can, to some degree, improve the prospects and decrease the cost of access to space within the current framework of the launching practices and technologies.

However, to make GOLF work big time and profitably, a new ground-to-orbit launching paradigm should be introduced, which would provide for the much lower than today ground-to-orbit cost of transportation coupled with the capability of an instant on-demand launch from GLH to orbit (Fig. 1).

As a multitude of the standard cargo containers will be fed along the ground-to-orbit leg, these containers will not need to carry the large or heavy cargos. It will be sufficient having only the relatively small containerized payloads of some dozens of kilograms shipped repeatedly from GLH to OLH to produce (3D printing) and/or assemble on the orbit whatever may be needed of any size, shape, or weight. 
The GOLF concept is based on the mentioned idea.

It calls exigently for a new ground-to-orbit launching paradigm for very small payloads.

The chemical rocket propulsion is the only type of propulsion in use for the ground-to-orbit launch. After almost a century of development, the upsides and downsides of the chemical rocket propulsion are well understood. Being technologically complex and operationally hazardous, it is too expensive (because of the low $\mathrm{I}_{\mathrm{sp}}$, necessity to carry a lot of fuel, high insurance fees, etc.) and limited in availability to adequately meet the existing, let alone the future, market needs.

If a much cheaper alternative to the chemical rocket propulsion launching paradigm is not found, then, no systematic and tangible advances in orbital (beyond the data collection and transmission) and deep-space activities should be ever expected aside from some sporadic, even if spectacular, missions (e.g., Apollo program or Rosetta mission).

Thus, the GOLF concept comes to grips with the fundamental issue of creating an inexpensive ground-to-orbit launching means, this boils down to the development of an adequate enabling propulsion technology for ground-to-orbit launch. The beamed propulsion is proposed as a suitable and practically feasible one for very small payloads.

\section{PIÈCE DE RÉSISTANCE}

Rockets are the momentum machines. In a conventional rocket, the fuel is chemically combined to provide energy and, the resulting combustion products are used as a working mass.

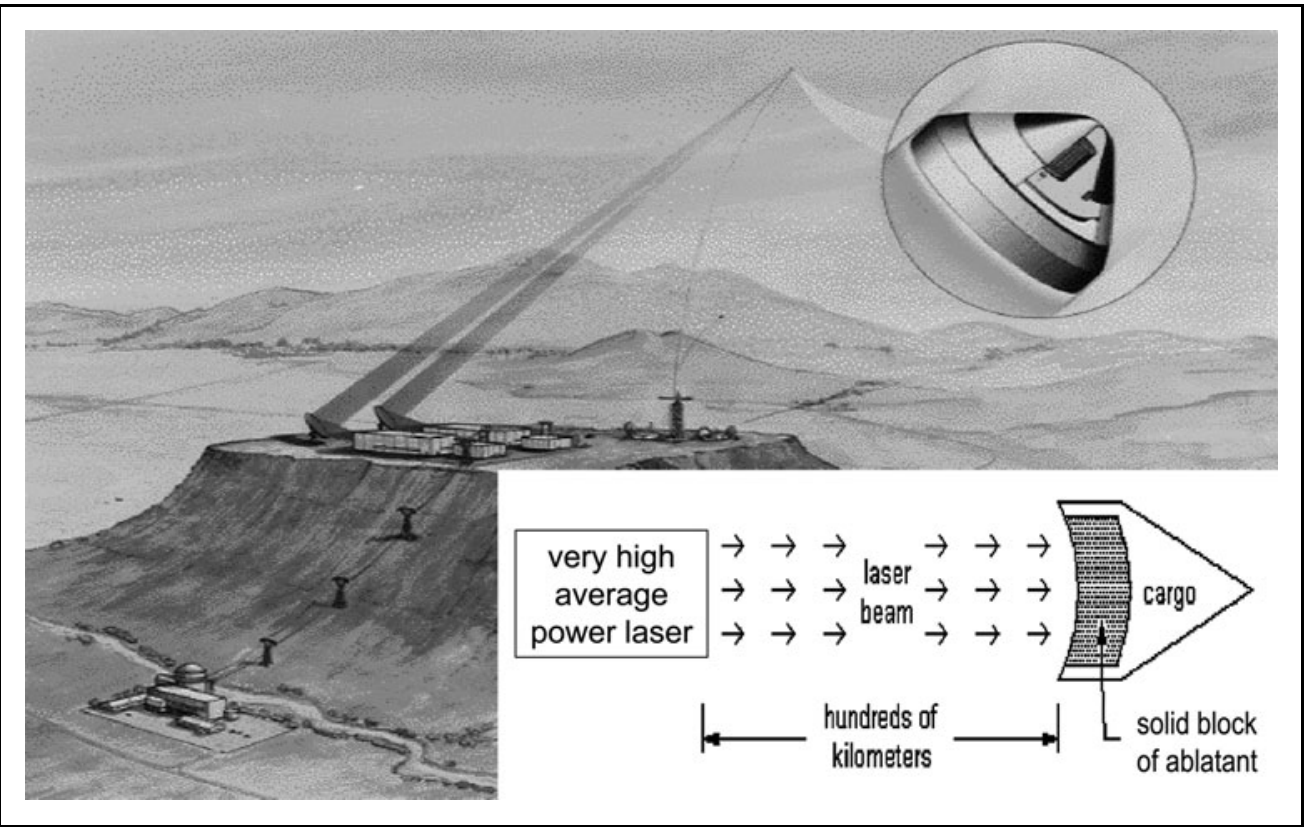

Fig. 2. Artistic view of the ground-to-orbit LAP system ${ }^{4}$. Figure adapted from Island One Society (www.IslandOne.org). LAP, laser ablation propulsion.
Removing the major energy source from the spacecraft can make a radical improvement.

Having a stationary energy source on the ground and delivering its energy through the atmosphere to the spacecraft to heat a propellant save the spacecraft from having to carry significant weight/volume and may greatly improve the rocket's performance (Fig. 2).

The proposed ground-to-orbit launching technology is based on the beamed energy propulsion enabled by laser. It is often called laser ablation propulsion (LAP). The implied thereafter laser's mode of operation is mostly pulse-repetitive.

LAP, being largely a quasi-neutral plasma type of propulsion, demonstrates the high specific impulse $\mathrm{I}_{\mathrm{sp}} \sim 7,500 \mathrm{~s} .{ }^{5,6}$ Achieving specific impulse of some tens kilo-seconds is possible with the current laser technology, ${ }^{7}$ also taking into account that the ion low thrust engines had already shown ${ }^{8} \mathrm{I}_{\mathrm{sp}} \sim 15,000 \mathrm{~s}$. Microwave propulsion can reach ${ }^{9} I_{\mathrm{sp}} \sim 900 \mathrm{~s}$, whereas the chemical rockets are limited to Isp $<500 \mathrm{~s}$ and have mostly Isp $<200 \mathrm{~s}$.

Along with the very high specific impulse, LAP can provide a thrust sufficient to propel small payloads of a few kilograms from ground to orbit. ${ }^{10-12}$

Thrust-to-weight ratio pertinent to the LAP engine was experimentally shown ${ }^{13}$ to reach 1,500 , which is by an order of magnitude higher than the thrust-to-weight ratios typically demonstrated by the chemical rockets and rocket engines. ${ }^{14}$

The LAP-to-LEO launch estimated mass ratio ${ }^{10}$ is $\sim 3.0$ and mass fraction ratio $\sim 0.6$ (despite LAP being inherently SSTO), whose values are much closer to those of the commercial aircraft performance than to those of the chemical rocket. ${ }^{15}$ This is good news for LAP.

Also, in laser ablation, plasma temperatures can be many times $10^{4} \mathrm{~K}$, and exhaust material can be chosen for optimum LAP mission parameters rather than simply for combustion efficiency. ${ }^{5}$

By varying intensity of the laser beam on target (on the ablatant's surface and/or in the neighboring plasma volume), a controlled variable exhaust velocity in a wide range of values can be achieved, which permits maximum efficiency flights ${ }^{16}$ where exhaust and flight velocity are matched.

Microwave propulsion, being a variety of beamed propulsion, has the technological pluses and 
minuses of its own. Very high power microwave-directed radiation, which is needed for ground-to-orbit launch, brings about the multiple concerns of its electromagnetic compatibility with the wireless terrestrial, aerial, orbital communication lines as well as the electronic and electromagnetic equipment. These concerns include the critical interference with the radar propagation (HF, VHF, UHF); navigation systems (GPS); scintillations of ground-to-satellite communications; generation of the ionospheric disturbances (artificial spread-F, enhanced airglow); and modification of the atmospheric electric field structure, possibly leading to the local thunderstorm enhancements. The powerful microwave transmissions across the atmosphere can significantly modify the natural ionosphere and alter the propagation of radio signals over a wide range of frequencies. ${ }^{17}$

LAP is virtually devoid of the mentioned concerns.

Use of optical wavelengths will minimize thermal blooming effects as compared with those of millimeter waves simply because the absorption coefficient is by 2 orders of magnitude less at optical wavelengths of most lasers than at millimeter wavelengths and, of course, diffraction effects dominate the longer wavelengths. ${ }^{18}$

The LAP overall efficiency depends on many factors such as the laser propulsion engine design and ablated materials, laser beam quality and its propagation through the atmosphere, specifics of the laser beam generation, and more.

In a simplified way, the final kinetic energy of a laser propelled vehicle $\mathrm{E}_{\mathrm{f}}$ can be presented as a product of several efficiencies and wall plug electric energy, $E_{\text {wall }}$ :

$$
\mathrm{E}_{\mathrm{f}}=1 / 2 \mathrm{mv}^{2}=\eta \alpha \beta \gamma \delta \mathrm{E}_{\text {wall }},
$$

where $\eta$ is propulsion efficiency (conversion of jet kinetic energy to vehicle kinetic energy),

$\alpha$ is absorption efficiency (conversion of laser energy into internal thermal energy of propellant),

$\beta$ is expansion efficiency (conversion of internal propellant energy into jet kinetic energy),

$\gamma$ is transmission efficiency (conversion of laser energy at ground to laser energy at vehicle), and

$\delta$ is laser efficiency (conversion of electric energy into the output laser energy).

LAP, in principle, permits maximum propulsion efficiency flights with $\eta=1$ by varying the intensity of laser beam to match the exhaust and flight velocities. To be on the safe side, $\eta=0.7$ is taken. For the chemically neutral propellants, the product $(\alpha \beta)$ is reported $d^{5,10,19,20}$ at $0.35-0.5$. Here the product is assumed as 0.4. Value of $\gamma$ depends on the lasing wavelength and varies widely with the atmospheric conditions. The lasing wavelengths of many powerful lasers $\left(\mathrm{DF}, \mathrm{CO}, \mathrm{CO}_{2}\right)$ allow the laser beam propagation from the ground across dry clear atmosphere to altitudes more than $50 \mathrm{~km}$ with efficiency more than $60 \%{ }^{21,22}$ Conservatively, $\gamma=0.5$ is considered. As a result, $(\eta \alpha \beta \gamma)$ is $\sim 0.14$, whereas $\delta \mathrm{E}_{\mathrm{wall}}=\mathrm{E}_{\text {out }}$.

For the time being let us focus on the laser's average output power $\mathrm{P}_{\text {out }}$ and laser output energy $\mathrm{E}_{\text {out }}$ rather than $\mathrm{E}_{\text {wall }}$ :

$\mathrm{E}_{\mathrm{f}}=1 / 2 \mathrm{mv}^{2}=\eta \alpha \beta \gamma \mathrm{E}_{\text {out }}=\eta \alpha \beta \gamma \mathrm{P}_{\text {out }} \cdot \mathrm{t}$,

(where $t$ is the active launching time).

The specific kinetic energy of a payload in LEO is about 32 $\mathrm{MJ} / \mathrm{kg}$. For a laser of average $\mathrm{P}_{\text {out }}=1 \mathrm{MW}$, we have approximately:

$\mathrm{m} \cdot 32 \mathrm{MJ}=\eta \alpha \beta \gamma \cdot 1 \mathrm{MW} \cdot \mathrm{t}$.

Thus, $1 \mathrm{MW}$ average power laser ablating a neutral propellant for 5 min can launch to LEO a little more than $1 \mathrm{~kg}$. The longer the launching time, the heavier the weight to LEO. Despite the simplicity of the mentioned estimation, it provides the figures of merit roughly similar to those of more accurate calculations. ${ }^{10-12,23}$ It was theoretically shown that $1 \mathrm{MW}$ average power laser in $700 \mathrm{~s}$ can deliver to LEO up to $6 \mathrm{~kg} .{ }^{10,24}$ Having the chemically energetic (instead of neutral) propellant ablated by laser would increase apparent value of the product $(\alpha \cdot \beta)$ up to 1.5 because of the laser-induced chemical detonation with its shock wave plasma acceleration mechanism. ${ }^{20}$ This could result in lifting up to $20 \mathrm{~kg}$ to LEO by laser of the same power over the same time.

Effectiveness of LAP can be further increased by addressing the instability of supersonic gas flow caused by shock waves that "choke" the inlet of the nozzle, reducing thrust. These effects can be coped with the help of additional laser ablation and plasma plume reconfiguring so that the gas flows closer to the interior walls of the supersonic nozzle and significantly improves the overall thrust. ${ }^{25,26}$ The laser ablation technique, which helps to make the supersonic gas flow more stable and with additional momentum, is often called "supersonic laser propulsion." ${ }^{26}$ The technique can pave the way for integrating the LAP system with the gas blasting nozzles of the spacecraft and, as it was found, can increase the speed of gas flow while reducing the amount of used ablatant. ${ }^{27}$ Achieving quasi-stability of the supersonic exhaust production and the momentum coupling coefficient of $\sim 10^{-3} \mathrm{~N} / \mathrm{W}$, which falls into the range of its optimum values for ground-to-orbit launch, ${ }^{5,10}$ is theoretically feasible with this technique subject to full scale experimental verification.

Attaining the robust $1 \mathrm{MW}$ average power laser performance will be an all-important milestone in LAP development. Potentially, dozens MW of average output power can be achieved from a single gas laser aperture, ${ }^{28}$ which would increase the LAP launching to LEO capacity to hundreds of kilograms and more. 
At the same time, significant RetD efforts have shown that the beam combining techniques ${ }^{29,30}$ for a large number of solid state lasers of lower power cannot produce a beam, which could meet the high average power, mode of operation, and beam quality requirements of LAP-to-LEO propulsion any soon.

The LAP-to-LEO flight development overall state-of-the-art can be considered as being at TRL4. ${ }^{31}$

\section{LAP-TO-LEO LAUNCH ECONOMIES}

To avoid possible confusion, a clear difference should be made between the market demand and market supply points of view on the launching services. For a buyer of the services (market demand), the market price they pay for a single launch (unit) is their cost per unit. For sellers (market supply), their cost of manufacturing and delivering the unit plus their unit margin make up a traded price per unit. ${ }^{32}$

Market studies/reports routinely prioritize a standpoint of the market demand and often treat prices as costs. The NASA benchmarks for second, third and fourth generations of launching systems were defined this way. ${ }^{2,3}$ They are referred to as the threshold costs of launch rather than the threshold market prices of launch, which would better correspond to their actual meaning.

The approach proposed in the previous section also allows for the estimation of the cost of lifting $1 \mathrm{~kg}$ payload to LEO by means of $1 \mathrm{MW}$ average power laser ablating a chemically neutral propellant for $5 \mathrm{~min}$. As $1 \mathrm{kWh}=3.6 \mathrm{MJ}$, the kinetic energy of $1 \mathrm{~kg}$ at LEO is $\sim 9 \mathrm{kWh}$. Dividing $9 \mathrm{kWh}$ by product $(\eta \alpha \beta \gamma)$ and by the assumed laser wall plug efficiency $\delta=0.3$ gives the estimated electric energy needed to launch $1 \mathrm{~kg}$ to LEO, which is almost $215 \mathrm{kWh}$. Electricity prices for medium size industrial companies range from 5 cents in Texas to more than 10 cents in the United Kingdom per kilowatt hour. ${ }^{33,34}$ Thus, the electric energy needed to launch $1 \mathrm{~kg}$ from Texas to LEO by a 1 MW laser with chemically neutral propellant and 5 min launching time would cost about $\$ 10$. With a chemically energetic propellant, $1 \mathrm{MW}$ laser operating for $5 \mathrm{~min}$ would be capable of launching to LEO about $5 \mathrm{~kg}$ with the specific energy cost less than $\$ 3 / \mathrm{kg}$.

Cost of energy is not the most important factor in the cost structure of the ground-to-orbit launch. Often it is almost negligible.

For example, the SpaceX's Falcon 9 rocket launch price tag is $\$ 62$ million, ${ }^{35}$ whereas the fuel and liquid oxygen (LOX) cost is approximately $\$ 200,000$ only, ${ }^{36}$ this represents $<0.5 \%$ of the total launching cost (at profit margin $<50 \%$ ).

Total LAP-to-LEO launch cost (seller's viewpoint) is made of the direct and indirect costs. The direct costs are mostly the costs of the vehicle structure and its manufacturing, the prelaunch preparations, and energy costs. The indirect costs account for amortization of the launch facility and Design, Development, Test \&t Evaluation (DDT\&E) program, plus the range and insurance costs.

Hereunder is given, as an example, a table of the costs calculated for launching to LEO a payload of $1,000 \mathrm{lb}$ $(\sim 453 \mathrm{~kg})$ by a conventional 2-stage expendable launch vehicle (ELV) powered by kerosene (RP-1) and LOX in the launching program of 500 flights over 10 years and DDT\&E cost of $\$ 50$ million (Table 2). ${ }^{37}$

The table shows the total specific cost of launch from the ground to LEO of approximately $\$ 3,300 / \mathrm{kg}(\$ 1,501 / \mathrm{lb})$, which is to say very optimistic for that small dedicated payload $(<500 \mathrm{~kg})$. Normally, for such small dedicated payloads, the launching companies quote their market prices by an order of magnitude higher ${ }^{38-41}$ so that, even if the targeted profit margin would be as lofty as 50\%, their launching to LEO total specific costs stay always $>\$ 15,000 / \mathrm{kg}$.

Let us take on the specific direct cost estimation both for conventional propulsion and for LAP. An overoptimistic estimation of the specific direct cost of launch to LEO of the dedicated small $(<500 \mathrm{~kg})$ payload by conventional ELV can be deduced from Table 2 . It is approximately $\$ 1,192 / \mathrm{kg}$ (\$540/lb).

For the LAP launch, presuming that the lower part of the atmosphere (up to $30-35 \mathrm{~km}$ of altitude) can be penetrated by LAP spacecraft in the ablatant-saving air-breathing mode of

\begin{tabular}{|c|c|}
\hline Vehicle Structure & 525,000 \\
\hline Propellant & 10,000 \\
\hline Prelaunch preparations & 5,000 \\
\hline Direct launch costs & 540,000 \\
\hline Amortized DDT\&E & 100,000 \\
\hline Amortized launch facility & 4,000 \\
\hline Range costs & 477,000 \\
\hline Insurance & 380,000 \\
\hline Indirect launch costs & 961,000 \\
\hline Total launch costs & $1,501,000$ \\
\hline Specific launch cost (per pound) & 1,501 \\
\hline
\end{tabular}

DDT\&E, Design, Development, Test \& Evaluation. 
operation, ${ }^{42,43}$ the specific direct cost of launching payload of $\sim 5 \mathrm{~kg}$ to LEO is calculated based on the mass budget of the LAP spacecraft ("heavy" flyer ${ }^{10}$ ) and pertinent market prices/ labor costs ${ }^{37,44}$ plus the estimated earlier specific cost of energy required for launch from the ground to LEO $(\$ 10 / \mathrm{kg})$, this results in approximately $\$ 90 / \mathrm{kg}$.

Dealing with and comparing the indirect costs are more challenging because LAP and chemical propulsion, in the context of launching payloads to orbit, are not at the same level of maturity neither technologically nor as to their market positioning. One can say that LAP is today where the chemical propulsion was at the beginning of the 1950s-on the verge of its very first space application.

Indirect specific costs estimation and comparison of LAP with conventional propulsion technologies are based on the following assumptions:

(1) The maturity level and market positioning of both technologies are deemed to be the same and as if they belong to the mainstream market.

(2) Mission programs are the same for both: 1,000 launches over 10 years (indirect cost gets lower than given in Table 2 because of the twice higher rate of flights). DDTEE cost is the same as used in Table 2.

(3) Owing to assumption (1), DDTEE costs must not be confused with the initial nonrecurring RAD costs (initial R\&D investment) relevant to creation of a new technology from scratch and/or raising it from the low to high TRLs, which is discussed later. LAP-to-LEO launch DDT\&E overall (10 years) specific cost is taken at $\$ 20,000 / \mathrm{kg}$. It is lowest in the range of applicable values pertinent to the historic U.S. ELVs DDTEE ${ }^{2}$ (as LAP spacecraft is relatively simple). This makes DDT\&E specific cost $\$ 20 / \mathrm{kg}$ per flight.

(4) The LAP-to-LEO launch specific range and launch site costs per flight are taken at $\$ 125 / \mathrm{kg}$ each based on the simulated data for laser propulsion mission (deduced from the relevant table). ${ }^{43}$

(5) LAP-to-LEO launch insurance costs should be comparatively low, thanks to the small size of the spacecraft, no risk of a violent explosion, and almost nonexistent ecological risks, all presumably resulting in the low maximum possible loss. As a matter of fact, in the United States, nanosatellites are exempt from insurance through support of the Government run Launch Initiative. Thus, the LAP-to-LEO insurance specific cost is taken at zero ${ }^{45}$ (Table 3).

The estimated LAP-to-LEO launch total specific cost is $\$ 360 / \mathrm{kg}$. Many prominent LAP experts agree that approxi- mately $\$ 300 / \mathrm{kg}$ is a plausible level of the LAP-to-LEO launch specific cost. $^{7,24}$

These estimates bespeak the future LAP-to-LEO launch total specific cost not exceeding $\$ 500 / \mathrm{kg}$ and tending to $\$ 300 / \mathrm{kg}$. According to NASA criteria, ${ }^{2,3}$ the LAP-to-LEO launch technology potentially belongs to the third generation of launch systems.

At the same time, the conventional launch systems continue struggling to get closer to second-generation launch system level and, for their most part, will never make it, except for the very large ELVs such as Falcon Heavy ( $>50$ tons of payload) if the launch market will support enough of their flights per year.

The third-generation launch system level is beyond the reach of conventional chemical propulsion rocket technology altogether.

In addition to the costs reflected in Table 3, there are also initial nonrecurring R\&D costs (initial R\&D investment), which are the one-time up-front costs for a new product development. When the initial RAD investment cannot be recovered in a habitual business manner, these costs must be considered as a loss, in the hope that it can be recovered from further profits on future operations/projects.

Table 3. LAP Versus Conventional Specific Launch Costs

Launching program

\begin{tabular}{l|l|c}
\hline Time, years & \multicolumn{2}{|c}{10} \\
\hline Number of launches a year & \multicolumn{2}{|c}{100} \\
\hline Payload, kilogram & 5.6 & 453 \\
\hline Type of propulsion & LAP & Chemical propulsion
\end{tabular}

Specific launch costs to LEO (\$ per kilogram of payload per launch)

\begin{tabular}{|c|c|c|}
\hline Vehicle structure & 29 & 1,159 \\
\hline Propellant + energy & 43 & 22 \\
\hline Prelaunch preparations & 18 & 11 \\
\hline Direct & 90 & 1,192 \\
\hline Amortized DDT\&E & 20 & 110 \\
\hline Amortized launch facility & 125 & 5 \\
\hline Range costs & 125 & 526 \\
\hline Insurance & 0 & 419 \\
\hline Indirect & 270 & 1,060 \\
\hline Total & 360 & 2,252 \\
\hline
\end{tabular}

LAP, laser ablation propulsion. 
A considerable initial R\&D investment is required to elevate TRLs of the LAP-to-LEO launch technology constituent parts including the high average power laser, LAP engine and spacecraft, tracking system, and other attendant subsystems.

Regardless of how low the LAP-to-LEO recurring and nonrecurring amortized costs (Table 3) may promise to be, their immediate attractiveness can be blocked by potential objections to the anticipated high initial RED investment (up-front losses). The LAP-to-LEO launch aspirations are likely to encounter a problem common to the pre-market stage of technology evolution often called "valley of death," also, aggravated by the nascent, although quickly emerging state of the small payloads dedicated launch market.

There are several estimates of how deep the "valley of death" (initial R\&D costs mostly) can be. Although some experts consider the valley's depth to be on the order of some billions, ${ }^{5,46}$ others measure it as a few hundred million only. ${ }^{47,48}$

As a remark, historically, if a few governments, for whatever reasons, would not start pouring money some 70 years ago into the rocket and jet chemical propulsion technology development, there would be no such thing as space industry nor modern aviation today. We might be still living in the turboprop age with no access to space.

The realities of modern life, however, are far and apart from those of the 1940s-1960s and may offer some new ways to tackle the difficult issues. Traversing the "valley of death" may require an intelligent blend of public and private sector investments. Analyzing it goes beyond the scope of this article.

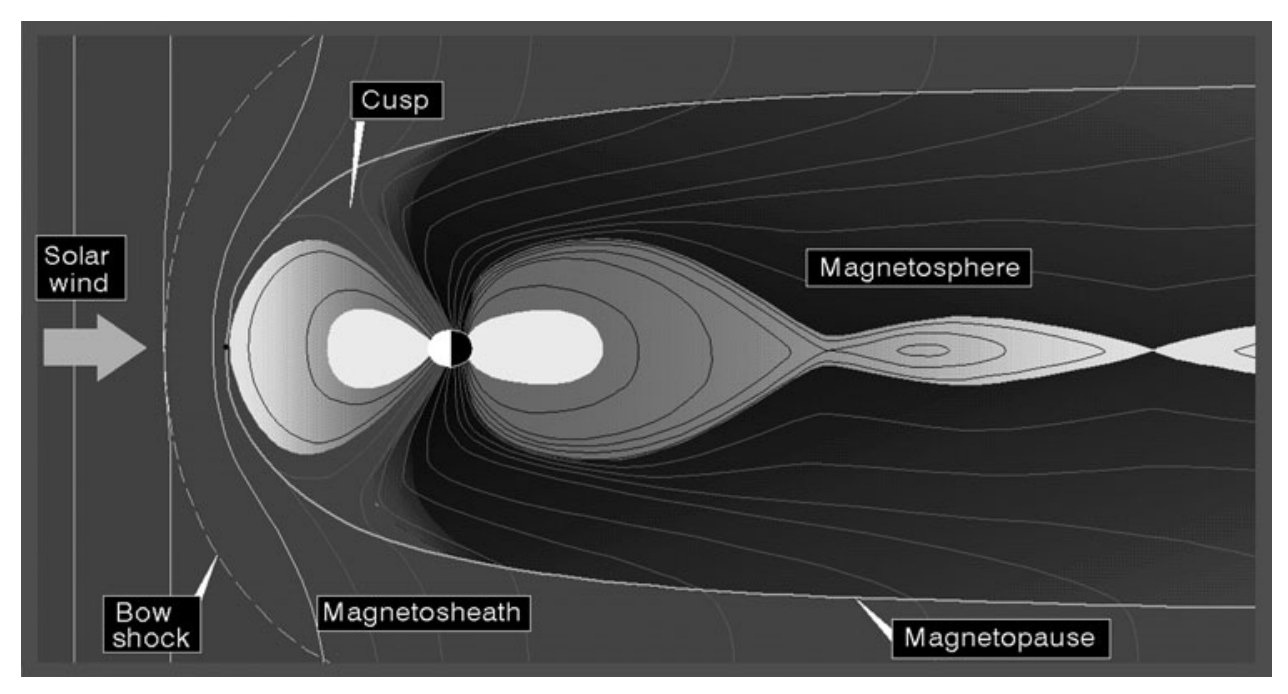

Fig. 3. Cross-section of the Earth's magnetosphere. ${ }^{49}$ Image from NASA (http://image.gsfc .nasa.gov).

\section{TWO NOTABLE ASPECTS OF GOLF}

A lucky circumstance favors the GOLF concept. The near Earth orbits, including the geostationary orbits, are protected from the most energetic and harmful cosmic rays and solar wind outbursts by the Earth's magnetosphere, which is $\sim 65$ '000 km high on the Earth's sunny side.

This is an important happenstance as OLH will be frequented by engineers and technicians building and, then, operating OLH as well as scientists and space tourists. The Earth's protective magnetosphere is an incredible force of nature, which should be appreciated and wisely availed of (Fig. 3).

Also, a general principle of the educational methodology supports the GOLF concept.

Namely, learning successfully requires ascending from the simpler to more complex topics and problems in a gradual manner and without too much of a gradient at any given time. Exactly for this reason, the whole schooling system is in place in society to provide a gradual systematic approach to learning. Without it, no space scientists/engineers would exist.

Venturing into space is a continuous learning process. Accordingly, learning to live and work in space on a large scale would be proper to start not on Moon or Mars, as some suggest, but in the Earth orbital environment protected from the harsh radiation. Using and expanding the accumulated experience of the earlier orbital stations and, most importantly, achieving and mastering the critical capability of accessing orbit from the ground at very low cost would be a timely goal for today and the immediate future. Having it attained will ensure the necessary grounds for the sound and systematic large-scale deep space and orbital activities.

The GOLF concept naturally embraces and promotes the mentioned approach.

\section{GOLF BUSINESS SERVICES}

GLH can provide the following services:

- space containers for rent,

- renting out the storage facilities,

- payload packaging and mounting services,

- launching the containerized cargo to OLH,

- direct dedicated launch of nano/micro satellites to their orbits, 
- beaming energy to satellites to effectuate their orbits corrections or batteries recharge, and

- letting authorized entities use the powerful laser for their orbital debris mitigation activities.

OLH can offer another set of business services:

- receiving, dismounting, unpackaging cargos;

- renting the orbital storage to third parties;

- conditioning and renting out the industrial facilities;

- conditioning and renting out the shipyard facilities;

- renting out the scientific User Lab facilities;

- renting out the cargo containers for downmass;

- downmass packaging and mounting services;

- assembling missions at the shipyard industrial facilities on demand;

- launching the deep space missions to their destinations;

- launching the satellites to their orbits;

- launching the downmass containers;

- providing orbital platform to third parties deep space manned missions;

- housing third party personnel and scientists;

- $3^{*}$ hotel for tourists (panoramic view, winter garden, restaurant, TV/Internet, sauna, etc.).

The foregoing may sound a little dreamlike but, in fact, many elements of the proposed concept were actually attempted at the orbital stations, including the recent releases of the nanosatellites from ISS.

However, prior proceeding with the GOLF's full realization, a means of overcoming the Earth's gravity and reaching orbit inexpensively, if only for the very small payloads, should be achieved.

Indeed, solely the task of lifting payloads from ground to orbit can form the initial economic basis for all future space activities. Without having the lifting task nonprohibitively priced, no significant future space activities will occur.

In the situation when no truly affordable access to space (i.e., third-generation launch systems) can be in principle effectuated by means of the conventional rockets, whether reusable or not, ${ }^{37,50}$ the only way to attend to the future space aspirations would be by focusing the efforts and investment on development of the third-generation launch system technologies.

The recently emerged market in launching the very small satellites by hundreds ${ }^{51-53}$ to LEO (with their replacement and orbit correction necessities in the offing) as well as the emerging needs in shipping downmass ${ }^{54}$ may serve as the catalysts for the promoted by GOLF third-generation LAPbased launching system rapid development.

\section{CONCLUSIONS}

1. It appears that segregating the ground-to-orbit flight from the in-space flight can provide a winning approach to solve the fundamental problem of accessing space inexpensively.

2. GOLF concept in its practical realization will depend heavily on development and availability of the inexpensive ground-to-orbit propulsion means for very small payloads.

3. LAP full-scale development, including the high average power laser, is positioned to enable the third-generation launch systems, which will make the GOLF concept realization feasible.

LAP-enabled launch systems will not compete with the conventional launching means on the powerful thrust and heavy payloads delivery to orbit. Instead, they will provide capacity for the very small payloads ground-to-orbit launching, very inexpensively, and as often as one may wish.

4. Successful implementation of the GOLF concept will eliminate, by and large, the bottleneck problem of accessing space (including downmass shipment).

It will make the future deep space activities possible on the increasingly large and systematic scale and, thus, may herald a dawn of the new industrialization era accompanied by a surge of the global markets and massive diverse innovation.

5. The arguments presented herein may imply that neither a significant expansion into deep space (as starting the deep-space industries or colonies) nor an impactful new orbital industry development (beyond the data collection and transmission) will ever be possible without creating an operationally inexpensive ground-to-orbit logistics framework functionally similar to the one described in this paper.

\section{ACKNOWLEDGMENTS}

Conceptual support of Jean-Jacques Dordain, former Director General of ESA, motivated having this article written. Valuable comments by Dr. Claude Phipps helped to improve quality of the manuscript. Practical aid by Aram Ekavian was very timely. To all of them, I extend my warm gratitude.

\section{AUTHOR DISCLOSURE STATEMENT}

No competing financial interests exist.

\section{REFERENCES}

1. https://en.wikipedia.org/wiki/Delta-v_budget (Last accessed on March 5, 2017).

2. Henry G. The Decision Maker's Guide to Robust, Reliable and Inexpensive Access to Space. Montgomery AL: Air University Press, 2003. 
3. Boeing, General Dynamics, LockheedMartin, Marietta, McDonnell Douglas, Rockwell. Commercial Space Transportation Study. Hampton VA: NASA Langley Research Center, 1994.

4. www.islandone.org/Propulsion/Lsrprp1.gif (Last accessed on March 5, 2017).

5. Phipps C, Michaelis M. LISP: Laser impulse space propulsion. Proc Las Part Beams. 1994;12(1):23-54.

6. Phipps C, Luke J, Helgeson W. 3ks Specific Impulse with a ns-pulse Laser Microthruster. Proc 29th Int Electric Propulsion Conf. 2005; Paper 319.

7. Phipps C, Bohn W, Lippert T, Sasoh A, Schall W, Sinko J. A review of laser ablation propulsion. AlP Proc. 2010;1278:710-22.

8. Owano $\mathrm{N}$. Ion space drive is said to break fuel efficiency record. TechXplore September 25, 2015. https://techxplore.com/news/2015-09-ion-space-fuelefficiency.html (Last accessed on March 5, 2017).

9. Parkin K. The Microwave Thermal Thruster and Its Application to the Launch Problem (Ph.D. dissertation). Pasadena CA: CalTech, 2006.

10. Phipps $C$, Reilly J, Campbell J. Optimum parameters for laser launching objects into low Earth orbit. Laser Part Beams. 2000;18(4):661-95.

11. Eckel H-A, Schall W. Concept for a laser propulsion based nanosat launch system. AIP Proc. 2004;702:263-73.

12. Scharring S, Eckel H-A. Review On Laser Lightcraft Research At DLR Stuttgart. Stuttgart DE: ITP DLR, 2013.

13. Rezunkov $Y$, et al. Performance Characteristics of Laser Propulsion Engine Operating both in CW and in Repetitively-Pulsed Modes. AIP Proc. 2006;830:3-13.

14. https://en.wikipedia.org/wiki/Thrust-to-weight_ratio (Last accessed on March 5, 2017).

15. https://en.wikipedia.org/wiki/Payload_fraction (Last accessed on March 5, 2017).

16. Larson $C$, Mead F, Knecht S. Benefit of Constant Momentum Propulsion for Large $\Delta$ V Missions-Applications in Laser Propulsion. AlAA 2004-0649. 42nd AIAA Aerospace Sciences Meeting and Exhibit 5-8 January 2004, Reno, Nevada.

17. Bain C. Potential of Laser for SPS Power Transmission. Springfield VA: NTIS US DOC, 1978

18. Manning R. Beamed-Energy Propulsion (BEP): Considerations for Beaming High Energy-Density Electromagnetic Waves Through the Atmosphere. NASA STI Program Report. Glenn Research Center. Cleveland, Ohio, May 2015.

19. Ageichik A, Repina E, Rezunkov Y, Safronov A. Detonation of CHO-propellants in a laser propulsion engine. J Tech Phys. 2009;54(3):402-9.

20. Larson $C$, Mead $F$, Knecht $S$. Laser propulsion and the constant momentum mission. AIP Proc. 2004;702:216-28.

21. Smith F, et al. Atmospheric Propagation of Radiation (The Infrared \& Electro-Optical Systems Handbook). Bellingham WA: SPIE Optical Engineering Press, 1993.

22. Measures R. Laser Remote Sensing. New York: John Wiley \&t Sons, 1984.

23. Schall W, Eckel H-A. Pulsed laser propulsion experiments. Space Technol. 2004; 24:129-35.

24. Phipps C, et al. Review: Laser-ablation propulsion. J Propul Power. 2010;26(4):609-37.

25. Meyer L. Supersonic laser-propelled rockets. OSA.org. 29 Oct. 2014. www.osa .org/en-us/about_osa/newsroom/news_releases/2014/supersonic_laser-propelled_ rockets/ (Last accessed on March 5, 2017).

26. Rezunkov Y, Schmidt A. Supersonic laser propulsion. Appl Opt. 2014;53(31):11-18.

27. Hunt G. Laser-propelled missiles-finally an environmentally friendly mode of space exploration. SiliconRepublic. 30 0ct. 2014. https://www.siliconrepublic .com/innovation/laser-propelled-missiles-finally-an-environmentally-friendlymode-of-space-exploration (Last accessed on March 5, 2017).

28. Pigulevski I. Laser propulsion market-creating innovation. New Space. 2016;4: 123-128.

29. Hecht J. Beam combining cranks up the power. LaserFocusWorld. June 1, 2012 www.laserfocusworld.com/articles/print/volume-48/issue-06/features/beamcombining-cranks-up-the-power.html (Last accessed on March 5, 2017).

30. Wallace J. $100 \mathrm{~kW}$ fiber laser, power meter serve industry. LaserFocusWorld. Dec 06, 2013. www.laserfocusworld.com/articles/print/volume-49/issue-12/worldnews/materials-processing-100-kw-fiber-laser-power-meter-serveindustry.html (Last accessed on March 5, 2017).
31. Technology Readiness Levels Handbook for Space Applications. European Union: ESA Document TEC-SHS/5551/MG/ap, 2008. https://artes.esa.int/sites/ default/files/TRL_Handbook.pdf (Last accessed on March 19, 2017).

32. https://en.wikipedia.org/wiki/Gross_margin (Last accessed on March 5, 2017).

33. A European Comparison of Electricity and Gas Prices for Large Industrial Consumers. Brussels BE: PwC Ent Adv, 2016.

34. European electricity prices and their components. Berlin DE: Ecofys Germany, 2013.

35. www.spacex.com/about/capabilities (Last accessed on March 5, 2017).

36. www.zmescience.com/space/spacex-reusable-rocket-100-times-cheaper-0432423 (Last accessed on March 5, 2017).

37. Jurist J, Dinkin S, Livingston D. When physics, economics, and reality collide: The Challenge of Cheap Orbital Access. AIAA Space Forum Proc. 2005. http://colonyfund .com/Reading/papers/phys_econ_2_leo.pdf (Last accessed on March 5, 2017).

38. Henry C. Rocket Lab declares Electron ready for test flights. Space News. December 13, 2016. http://spacenews.com/rocket-lab-declares-electron-readyfor-test-flights (Last accessed on March 5, 2017).

39. Coopersmith J, Davis E. A Strategic Roadmap for Commercializing Low-Cost Beamed Energy Propulsion Launch Systems. AIAA Space Conf Proc. 2016:5555. http://arc.aiaa.org/doi/abs/10.2514/6.2016-5555 (Last accessed on March 5, 2017).

40. State of the Satellite Industry Report. Alexandria VA: Tauri Group, 2016. www.sia.org/wp-content/uploads/2014/09/SSIR-September-2014-Update.pdf (Last accessed on March 5, 2017).

41. Writers S. New small launch vehicles. Space Daily. April 26, 2016. www.spacedaily .com/reports/New_small_launch_vehicles_999.html (Last accessed on March 5, 2017).

42. Myrabo L, Ing D. The Future of Flight. New York: Baen Books-Simon and Schuster, 1985.

43. Davis E, Mead Jr. F. Review of laser lightcraft propulsion system. AIP Conf Proc. 2008;977:283-94.

44. www.alibaba.com/showroom/pom-sheet-price-of-delrin-per-kg.html (Last accessed on March 5, 2017)

45. www.nesta.org.uk/crafting-better-space-industry-policy (Last accessed on March 5, 2017)

46. George P, Beach R. Beamed-Energy Propulsion (BEP) Study. NASA/TM-2012217014. Cleveland OH: Glenn Research Center, 2012

47. Rezunkov Y. Laser technologies for space. Laser-Inform. 2012;22(493):1-6. (in Russian).

48. Kare J. Pulsed laser propulsion for low cost, high volume launch to orbit. Space Power J. 1990;9:1-6.

49. //image.gsfc.nasa.gov/poetry/magnetism/magnetism.html (Last accessed on March 5, 2017).

50. Wertz J. Economic Model of Reusable vs. Expendable Launch Vehicles. Rio de Janeiro: IAF Congress Proc., 2000

51. Buchen E, Pasquale D. Nano/Microsatellite Market Assessment. Atlanta GA: SpaceWorks Enterprises, Inc., 2014

52. Pagliery J. Billionaires battle for the Internet in space. CNN Money. January 21, 2015. money.cnn.com/2015/01/21/technology/internet-in-space/index.html (Last accessed on March 5, 2017).

53. Henry C. OneWeb gets $\$ 1.2$ billion in SoftBank-led investment. Space News. December 19, 2016. http://spacenews.com/oneweb-gets-1-2-billion-in-softbankled-investment (Last accessed on March 5, 2017).

54. Taylor D. Space manufacturing and the last mile. Space News. December 28, 2016. http://spacenews.com/space-manufacturing-and-the-last-mile (Last accessed on March 5, 2017).

Address correspondence to: Iouri Pigulevski

DLTECH Institute Avenue des Sciences 3 Yverdon-les-Bains 1400 Switzerland

E-mail: dltech.ch@gmail.com 